\title{
Development and Optimization of an HPLC-PDA Method for the Determination of Major Cannabinoids in Hemp (Cannabis sativa L.) Essential Oil Obtained by Hydrodistillation
}

\author{
Barbara Piani $^{1} \cdot$ Claudio Ferfuia $^{1}$ D $\cdot$ Renzo Bortolomeazzi $^{1} \cdot$ Giancarlo Verardo $^{1} \cdot$ Mario Baldini $^{1}$
}

Received: 24 April 2021 / Accepted: 21 February 2022 / Published online: 2 March 2022

(c) The Author(s) 2022, corrected publication 2022

\begin{abstract}
The use of hemp (Cannabis sativa L.) essential oil (EO) has shown a significant increase in interest and use during recent years. In this work, a new and simple reversed-phase HPLC with photodiode-array (PDA) detector method has been developed and optimized for the detection and quantification of cannabidiolic acid (CBDA), cannabidiol (CBD), cannabinol (CBN), $\Delta$ 9-tetrahydrocannabinol ( $\Delta$ 9-THC), and $\Delta$ 9-tetrahydrocannabinolic acid (THCA). The cannabinoids were extracted from the EO by partition with $n$-hexane and water, followed by sonication, evaporation to dryness under nitrogen, and reconstitution with methanol:chloroform $(9: 1, \mathrm{v} / \mathrm{v})$ before HPLC-PDA analysis. The method shows good selectivity and robustness, linearity in the range $0.5-100 \mathrm{mg} \mathrm{L}^{-1}$ with $R^{2}$ higher than 0.999 for all cannabinoids analyzed, LOD of $0.11-0.16 \mathrm{mg} \mathrm{L}-1$, and LOQ of $0.35-0.48 \mathrm{mg} \mathrm{L}^{-1}$. The recovery was between 78 and $100 \%$ and the intra-day and intermediate precision, expressed as relative standard deviation (RSD), was $<4 \%$ and $4-10 \%$, respectively.
\end{abstract}

Keywords Hemp · Hemp essential oil · HPLC method optimization · Cannabinoids · Cannabis sativa L. · hydrodistillation

$\begin{array}{ll}\text { Abbreviations } \\ \text { CBDA } & \text { Cannabidiolic acid } \\ \text { CBD } & \text { Cannabidiol } \\ \text { CBN } & \text { Cannabinol } \\ \Delta 9-\text { THC } & \Delta \text { 9-Tetrahydrocannabinol } \\ \text { THCA } & \Delta \text { 9-Tetrahydrocannabinolic acid } \\ \text { CBCA } & \text { Cannabichromenic acid } \\ \text { ACN } & \text { Acetonitrile } \\ \text { MeOH } & \text { Methanol } \\ \text { EO } & \text { Essential oil } \\ \text { QC } & \text { Quality control } \\ \text { LQC } & \text { Low-quality control } \\ \text { MQC } & \text { Medium-quality control } \\ \text { HQC } & \text { High-quality control } \\ \text { IS } & \text { Internal standard } \\ \text { RP-HPLC } & \text { Reverse-phase high-performance liquid } \\ & \text { chromatography } \\ \text { PDA } & \text { Photodiode-array }\end{array}$

Claudio Ferfuia

claudio.ferfuia@uniud.it

1 Department of Agriculture, Food, Environment and Animal Sciences (Di4A), University of Udine, via delle Scienze 206, 33100 Udine, Italy

\section{Introduction}

The Cannabis genus belongs to the Cannabaceae family, order of the Rosales, and it is considered a monotypic genus that includes only the Cannabis sativa L. species with a wide genetic variability (Hazekamp 2007; Clarke and Merlin 2016; Koren et al. 2020). This species includes some subspecies, such as industrial or fiber hemp (Glivar et al. 2020) and drug or marijuana strains; the latter are cultivated and used only for medical-therapeutic purposes.

The cultivation of industrial hemp is regulated by national laws and allowed in several European countries only for monoecious and dioecious varieties registered in the EU plant variety database, containing less than $0.2 \%$ of the psychoactive $\Delta 9$-THC (Commission of the European Communities 2004). This crop, native to Asia and Indian subcontinent, today is grown in many countries (Sandler and Gibson 2019), with a strong increase in the use of its processed products in the manufacturing of paper, varnishes, inks, and biofuel, and in the phytoremediation, food and animal feed, medicine, nutraceuticals, cosmetics, and construction industries (Callaway 2004; Rehman et al. 2013).

Hemp EO is considered a niche product with high benefits and broad potential uses (Mediavilla and Steinemann 1997; Bertoli et al. 2010) from the cosmetic to the 
medical-pharmaceutical industry due to its natural antioxidant and antimicrobials (against Candida spp.) properties (Novak et al. 2001; Nissen et al. 2010; Nafis et al. 2019). Hemp EO has also been shown to have anti-leishmaniasis activities (Wanas et al. 2016), insecticidal and larvicidal activity against Aedes aegypti larvae (Górski et al. 2016; Bedini et al. 2016; Wanas et al. 2020), nematocide (Mukhtar et al. 2013), fungicide properties (Wielgusz et al. 2012), and allelopathic effect (Synowiec et al. 2016) finding utilization also in crop protection (Górski et al. 2016). Its use in the food sector is also very interesting and promising as flavoring for beverages and additives in pastry and catering (Meier and Mediavilla 1998).

Among the several methods employed to obtain EO from plant tissue, hydrodistillation is widely used as the official technique and adopted by the Official Pharmacopoeia of the Italian Republic (Commissione Permanente per la Revisione e la Pubblicazione della Farmacopea Ufficiale 2008). This technique extracts most of the volatile compounds present in the aromatic resins located mainly on the bracts that surround female flowers and fruits of the hemp plant (Kim and Mahlberg 1991; Meier and Mediavilla 1998; Andre et al. 2016). Hemp EO is a complex mixture of many volatile compounds, mainly terpenes and other minor substances like terpenoids that play different biological roles in the Cannabis sativa plants (Hazekamp 2007). Terpenes are a complex mixture of volatile compounds as monoterpenes, which are the main responsible for the fragrance (e.g., $\alpha$-pinene, myrcene, and terpinolene) and sesquiterpenoids ( $\alpha$-humulene, $(E)$-caryophyllene, and caryophyllene oxide) (Hillig 2004; Happyana and Kayser 2016). Cannabinoid compounds can be hydrodistilled together with terpene constituents; however, their concentration in the hemp EO is lower if compared to the inflorescence, being only partially water-distillable due to their low volatility (Kim and Mahlberg 1991; Mediavilla and Steinemann 1997).

Recently, Fiorini et al. (2020) applying the microwaveassisted extraction (MAE) method associated with hydrodistillation to hemp dried inflorescences obtained a higher yield of EO with an enrichment in bioactive compounds, especially cannabidiol (CBD), with respect to the conventional hydrodistillation.

Cannabinoids, exclusively present in Cannabis (Raharjo and Verpoorte 2004), reach their maximum content in plant resin close to flowering time (Pacifico et al. 2007). They are a group of terpenophenolic compounds characterized by a structure with 21 carbon atoms (Mukhtar et al. 2013) and currently about 113 compounds have been identified (Aizpurua-Olaizola et al. 2016). The most common types of cannabinoids present in the plant shared a carboxyl group: $\Delta$ 9-tetrahydrocannabinolic acid (THCA), cannabidiolic acid (CBDA), and cannabicromenic acid (CBCA). The carboxyl group however is not very stable and is easily lost as carbon dioxide, upon exposure to heat and light, particularly during collection, processing, and storage. The loss of the carboxyl group results in the conversion of the acids into their corresponding neutral and active form $\triangle 9-\mathrm{THC}, \mathrm{CBD}$, and CBC. Moreover, some cannabinoids are the result of the degradation of other cannabinoids, such as cannabinol (CBN) produced by the non-enzymatic oxidation of $\Delta 9$-THC under the effect of heat and light (De Backer et al. 2009). $\Delta 9$-THC is the main active compound responsible for psychoactive and physiological effects in humans, and many countries, including Italy, have recently established the maximum limits of total $\Delta 9$-THC admissible in food at $2 \mathrm{mg} \mathrm{kg}^{-1}$ for seed, flour, and supplements containing foods derived from hemp (Ministero della Salute 2020). Among non-psychotropic cannabinoids, CBD is undoubtedly the most interesting for its therapeutic and medicinal proprieties (Vági et al. 2019) and several new CBD products are utilized as alternative treatments, especially as beneficial for the symptomatology of health-related problems such as pain, anxiety, and inflammation (Corroon and Phillips 2018; Poleg et al. 2019).

Nowadays, high-performance liquid chromatography (HPLC) and gas chromatography mass spectrometry (GCMS) are the two most utilized and validated techniques for the analysis of cannabinoids in Cannabis plant materials and derived food products (inflorescence, seeds, seed oil, flour, etc.; De Backer et al. 2009; Citti et al. 2018), with the exception of EO. In particular, HPLC-based methods allow a better speciation between the acidic and decarboxylated forms of cannabinoids with respect to those employing GC-MS, in which high temperatures, necessary for the analysis, have as a consequence the decarboxylation of the acid compounds, leading to possible overestimation of their corresponding neutral forms (De Backer et al. 2009; Citti et al. 2018).

The aim of this work was to develop a simple and reliable HPLC-PDA method for the detection and quantification of five cannabinoids, namely CBD, CBDA, $\triangle 9$-THC, THCA, and CBN, focusing on hemp EO obtained by hydrodistillation.

\section{Materials and Methods}

\section{Standard and Chemicals}

Standards of cannabidiolic acid (CBDA), cannabidiol (CBD), cannabinol (CBN), (-)-trans- $\Delta$ 9-tetrahydrocannabinol ( $\Delta$ 9-THC), and $\Delta 9$-tetrahydrocannabinolic acid (THCA), as reference material (Cerilliant $\left.{ }^{\circledR}\right)$ certified at a concentration of $1.0 \mathrm{mg} \mathrm{mL}^{-1}$ methanolic solution and benzo[ghi] perylene (99.1\%), as internal standard, were purchased from Sigma-Aldrich Chemicals (Milan, Italy); HPLC grade methanol $(\mathrm{MeOH})(>99.9 \%)$, chloroform $(>99.9 \%), n$-hexane $(>95.0 \%)$, acetonitrile $(\mathrm{ACN})(>99.9 \%)$, and formic acid 
(99\%, LC/MS grade) were from Carlo Erba (Milan, Italy). The water was purified by Milli-Q ${ }^{\circledR}$ IQ 7000 water purification system from Millipore (Merck, Darmstadt, Germany).

\section{Preparation of Standard Solutions}

Working standard solutions of analytes were obtained after dilution of the reference standards with a mixture of $\mathrm{MeOH}$ :chloroform $(9: 1, \mathrm{v} / \mathrm{v})$. All stock and working standard solutions were stored at $-20{ }^{\circ} \mathrm{C}$, without showing any degradation up to 90 days.

Quality control (QC) samples were prepared by spiking hemp EO samples $(20 \mathrm{mg})$ at three concentration levels for all cannabinoids. The concentration levels were denoted as low-quality control (LQC) with a concentration of 0.2 $\mathrm{mg} \mathrm{g}^{-1}$ for CBDA, CBN, $\triangle 9$-THC, and THCA; mediumquality control (MQC) with a concentration of $1.0 \mathrm{mg} \mathrm{g}^{-1}$ for CBDA, CBN, $\triangle 9$-THC, and THCA; high-quality control (HQC) with a concentration of $2.5 \mathrm{mg} \mathrm{g}^{-1}$ for CBDA and THCA and $5.0 \mathrm{mg} \mathrm{g}^{-1}$ for CBN and $\Delta 9$-THC. In the case of CBD, due to the high amount of this compound in the EO, only two concentration levels were prepared (LQC and HQC) with a concentration of 1.0 and $5.0 \mathrm{mg} \mathrm{g}^{-1}$, respectively.

\section{Cannabis Samples}

The female inflorescences of Antal, a hemp dioecious variety, were utilized. Plants were grown at an experimental farm of Udine University, Udine, Italy (N $46^{\circ} 04^{\prime} 00^{\prime \prime}$, E $13^{\circ} 23^{\prime} 00^{\prime \prime}, 109 \mathrm{~m}$ a.s.1.) in 2016. The European Union only allows the cultivation of hemp varieties registered in the EU plant variety database (European Parliament and of the Council 2013), with a $\Delta 9$-THC content not exceeding $0.2 \%$, such as Antal. Five samples of female hemp inflorescences were collected manually at full flowering and immediately stored at $-20{ }^{\circ} \mathrm{C}$.

\section{Essential Oil Extraction and Sample Preparation}

The frozen fresh inflorescences were thawed and submitted to EO extraction by hydrodistillation, using a Clevenger-type apparatus, fitted to essential oils with low density. Briefly, $100 \mathrm{~g}$ of inflorescence were cut with scissors and placed in a round bottomed flask and $600 \mathrm{~mL}$ of distilled water were added. The flask was connected to the apparatus and the condensate flow was adjusted to $2 \mathrm{~mL} \mathrm{~min}^{-1}$. Distillation continued for $3 \mathrm{~h}$ (Vuerich et al. 2019). The EO was then dried over anhydrous $\mathrm{MgSO}_{4}$, filtered over cotton, and stored at room temperature for the HPLC-PDA analysis. The yield of EO was expressed as percentage v/w d.m. (dry matter, oven $105^{\circ} \mathrm{C}$ for $24 \mathrm{~h}$; AOAC Official Methods 934.01, 2016). The EO yield was expressed as d.m. due to the different water contents in hemp plants and to compare our data with those of other authors.

Twenty milligrams of EO were weighed in $15-\mathrm{mL}$ polypropylene tubes; then, $50 \mu \mathrm{L}$ of a benzo[ghi]perylene acetone solution (1120 mg L $\mathrm{m}^{-1}$ ), as internal standard (IS), 1 $\mathrm{mL}$ of $n$-hexane, and $1 \mathrm{~mL}$ of water were added and the sample was briefly vortexed and sonicated for $15 \mathrm{~min}$ in an ultrasound bath, LBS 2 (Falc Instruments Srl, Treviglio (BG), Italy). After sonication, the sample was centrifuged at $1157 \mathrm{~g}$ for $15 \mathrm{~min}$ on a Centrifuge 5804R (Eppendorf AG, Germany). Then, $700 \mu \mathrm{L}$ of supernatant was transferred in a glass tube, evaporated to dryness under nitrogen, reconstituted with $500 \mu \mathrm{L}$ of $\mathrm{MeOH}$ :chloroform $(9: 1, \mathrm{v} / \mathrm{v})$, vortexed, and filtered through syringe filters (PTFE $0.22 \mu \mathrm{m}, 25 \mathrm{~mm}$, DTO Servizi Srl, Venice, Italy). The filtrate was transferred into an autosampler vial and $10 \mu \mathrm{L}$ was injected into HPLC.

The same preparation procedure, including all solvents but without EO, was used to obtain reagent blank in order to exclude the presence of interfering compounds eluted with the same retention times of the analytes in the HPLC analysis.

\section{HPLC-PDA Chromatographic Conditions}

The HPLC system included a Shimadzu LC-20AT pump, a vacuum degasser, a Prominence SPD-M20A photodiodearray detector, a Prominence SIL-20AC HT autosampler (10 $\mu \mathrm{L}$ loop), and a Prominence CTO-20AC column oven set at $25{ }^{\circ} \mathrm{C}$ (Shimadzu Corporation, Kyoto, Japan). The HPLC separation was achieved using a Poroshell 120 EC-C18 column $(4.6 \times 150 \mathrm{~mm}, 2.7 \mu \mathrm{m}$ particle size, Agilent Technologies, Santa Clara, CA). Equipment control, data acquisition, and integration were performed with Shimadzu LabSolutions (Ver. 5.54 SP2) Software. A binary gradient of 0.1\% formic acid solution in water (A) and $0.1 \%$ formic acid solution in ACN (B) at a flow rate of $0.40 \mathrm{~mL} \mathrm{~min}{ }^{-1}$ was optimized. The gradient started at $70 \%$ of $\mathrm{B}$ for $5 \mathrm{~min}$, and then increased linearly to $77 \%$ of B in 7 min and at $90 \%$ of B in $0.10 \mathrm{~min}$. This composition was kept constant up to $30 \mathrm{~min}$ before a linear decrease to the initial conditions ( $70 \%$ of B) in $0.10 \mathrm{~min}$ and held up to $60 \mathrm{~min}$ for the equilibration of the column. The optimum wavelength detection for all cannabinoids was found to be $220 \mathrm{~nm}$ and the detector slit width was $4 \mathrm{~nm}$. Full spectra were recorded in the range 190-400 nm.

\section{Analytical Performance of the HPLC Method}

To assess the analytical performance of the method, the following analytical parameters were evaluated: selectivity, linearity, limit of detection, limit of quantitation, accuracy, precision, carry-over, stability, and robustness. 


\section{Selectivity}

The selectivity of the method was assured by comparison of the UV spectra of the analytes with those of the corresponding standard compounds and by the peak purity check.

\section{Linearity}

Calibration curves were prepared at seven calibration levels: $0.5,1.0,5.0,10,20,50$, and $100 \mathrm{mg} \mathrm{L}^{-1}$, for CBDA, CBD, CBN, $\triangle 9$-THC, and THCA, and $40 \mathrm{mg} \mathrm{L}^{-1}$ of IS. The standard solutions were freshly prepared before use. Each standard solution was analyzed six times and the average peak area ratios of each cannabinoid vs IS were plotted against the corresponding concentration ratios. Before each analysis session, a standard solution $\left(10 \mathrm{mg} \mathrm{L}^{-1}\right)$ was analyzed three times and the average relative response factor of cannabinoids with respect to the internal standard was calculated.

\section{Limit of Detection (LOD) and Limit of Quantitation (LOQ)}

LOD was determined by the analysis of reagent blank and EO diluted samples by establishing the minimum level at which the analytes could be detected, based on a signal-tonoise ratio of $3: 1(\mathrm{~S} / \mathrm{N}=3)$. LOQ was determined by following the same procedure and by establishing the minimum level at which the analytes could be quantified, based on a signal-to-noise ratio of 10:1 $(\mathrm{S} / \mathrm{N}=10)$. The parameters LOD and LOQ were calculated by using the instrument software.

\section{Accuracy and Precision}

The accuracy was assessed by recovery studies using the QC samples LQC, MQC, and HQC, prepared as reported in the "Preparation of Standard Solutions" section and expressed as percentage recovery $(\% \mathrm{R})$. Three separate replicates were carried out for each recovery level.

The precision was evaluated by analyzing three separate replicates of the LQC, MQC, and HQC samples on the same day (intra-day repeatability) and two separate replicates of the LQC and MQC solutions over a period of 3 days (intermediate precision). The results were expressed as relative standard deviation (RSD).

\section{Carry-Over}

To check the carry-over, the reagent blank prepared as reported in "Essential Oil Extraction and Sample
Preparation" section was injected in the HPLC system in between the EO samples.

\section{Stability}

Stability experiments were performed in triplicate by keeping the MQC samples of CBDA, CBN, $\triangle 9$-THC, and THCA and the $\mathrm{LQC}$ sample of $\mathrm{CBD}$ at room temperature for 7 days and at $-20{ }^{\circ} \mathrm{C}$ for 90 days.

\section{Robustness}

To evaluate the influence of small variations of the chromatographic parameters on the analytical results, a robustness study was carried out by varying, in a narrow range, the column oven temperature $25 \pm 5{ }^{\circ} \mathrm{C}$ and the flow rate 0.40 $\pm 0.05 \mathrm{~mL} \mathrm{~min}^{-1}$.

\section{Statistical Analysis}

Statistical analysis was performed using the software $\mathrm{R} v$. 4.0.0 (R Core Team 2020). The R script for contour plot was adapted from https://yuanbofaith.github.io/RK_LCMS/ (Yuan et al. 2020).

\section{Results and Discussion}

\section{Method Development}

The HPLC-PDA chromatogram of a standard mixture of five cannabinoids at $60 \mathrm{mg} \mathrm{L}^{-1}$ and IS is reported in Fig. 1. The chromatogram shows a good separation of the cannabinoids with retention time in the range 15-26 min, whereas the IS retention time was $30 \mathrm{~min}$. The cannabinoids elution order was CBDA, CBD, CBN, $\triangle 9$-THC, and THCA. The UV spectra (190-400 nm) of the cannabinoids standards, recorded by the PDA detector and used to prepare a spectral library, are reported in the same figure.

Attempts were carried out in order to analyze directly the EO, after a simple dilution, before the HPLC analysis. The resulting chromatograms were, however, characterized by the presence of many intense peaks due to monoterpene and sesquiterpene hydrocarbons, which interfered with the quantification of cannabinoids. Partition of EO components between water and $n$-hexane resulted in a cleaner extract, free of interfering compounds in the elution zones of the cannabinoids of interest. Moreover, for the optimization of the analytical method, preliminary analyses were carried out by using the QC samples in order to have an EO sample containing all the analytes of interest.

The chromatograms of an EO sample (A) and of the HQC sample (B) are showed in Fig. 2. The analytes were 
Fig. 1 HPLC-PDA chromatogram of a standard mixture of cannabinoids at $60 \mathrm{mg} \mathrm{L}^{-1}$ and their corresponding UV spectra
Datafile Name:StdSmixli_24giugno003.lcd
Sample Name:Std 3 3

$\mathrm{mAU}$

$220 \mathrm{~nm}, 4 \mathrm{~nm}$
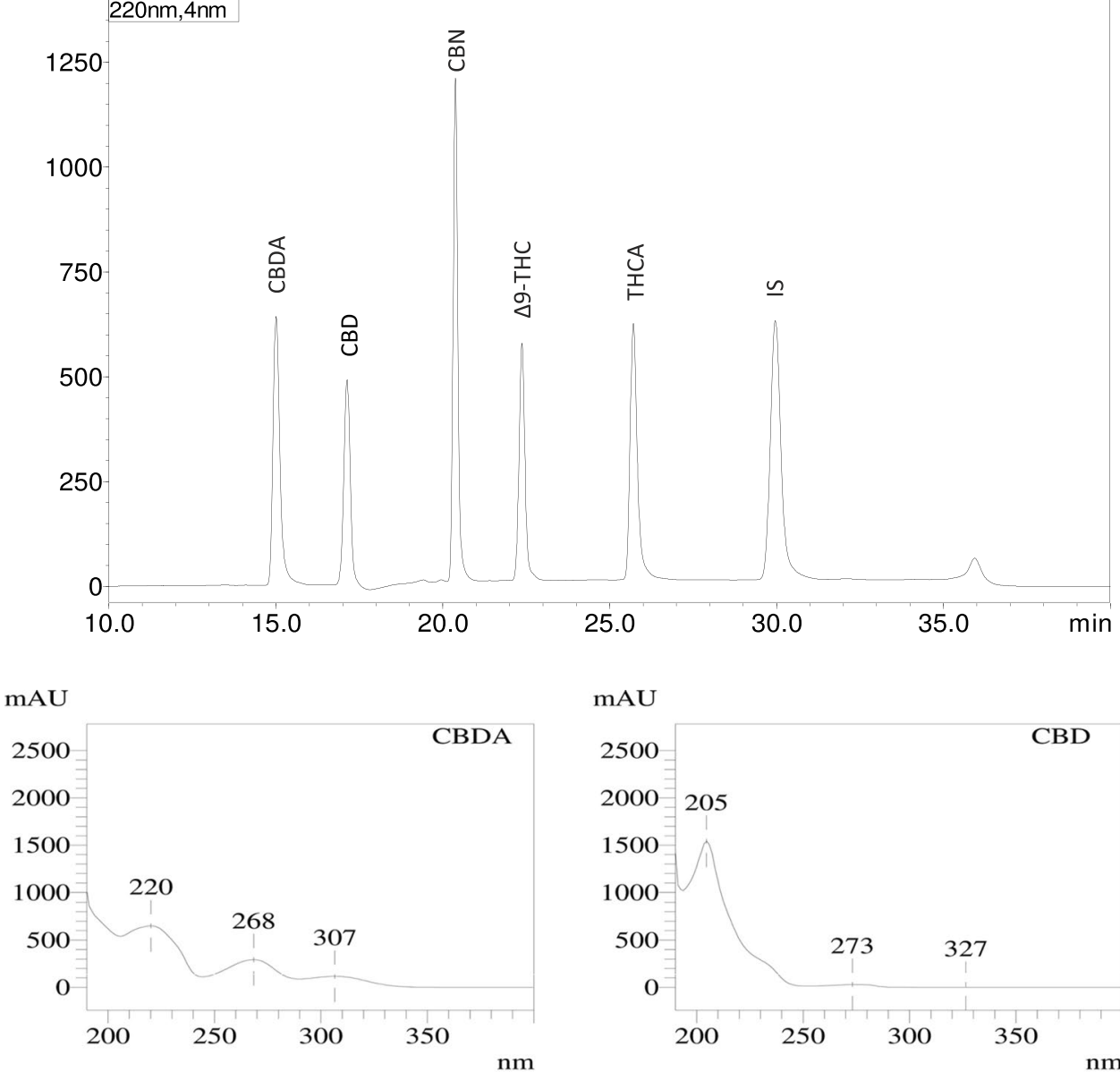

mAU

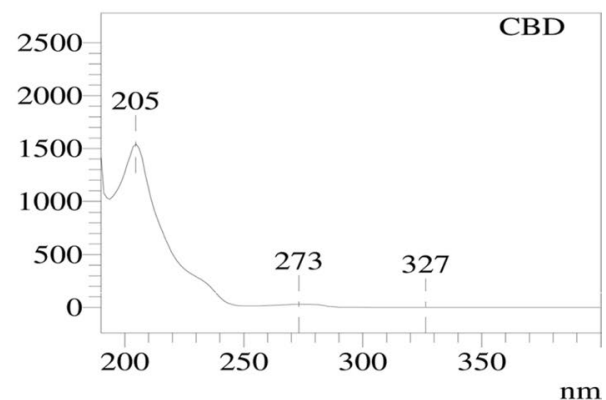

mAU

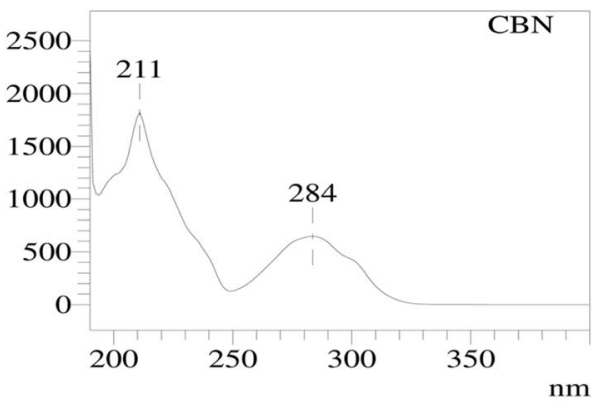

mAU

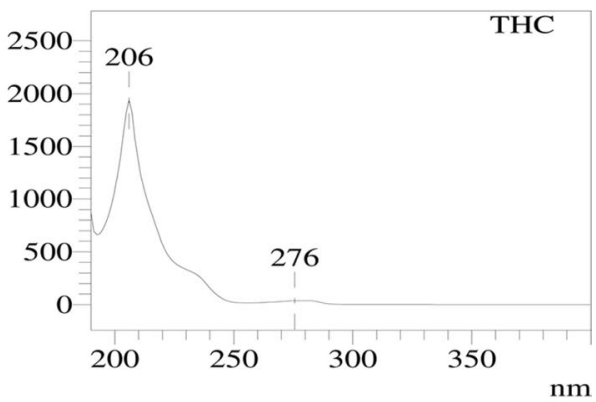

mAU

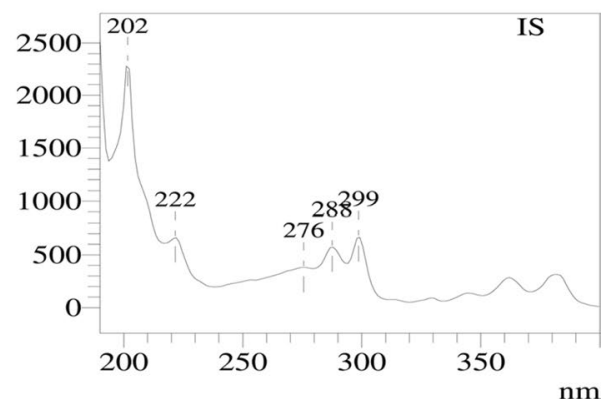


Fig. 2 HPLC-PDA chromatogram of an EO sample (A) and of the HQC sample (B)
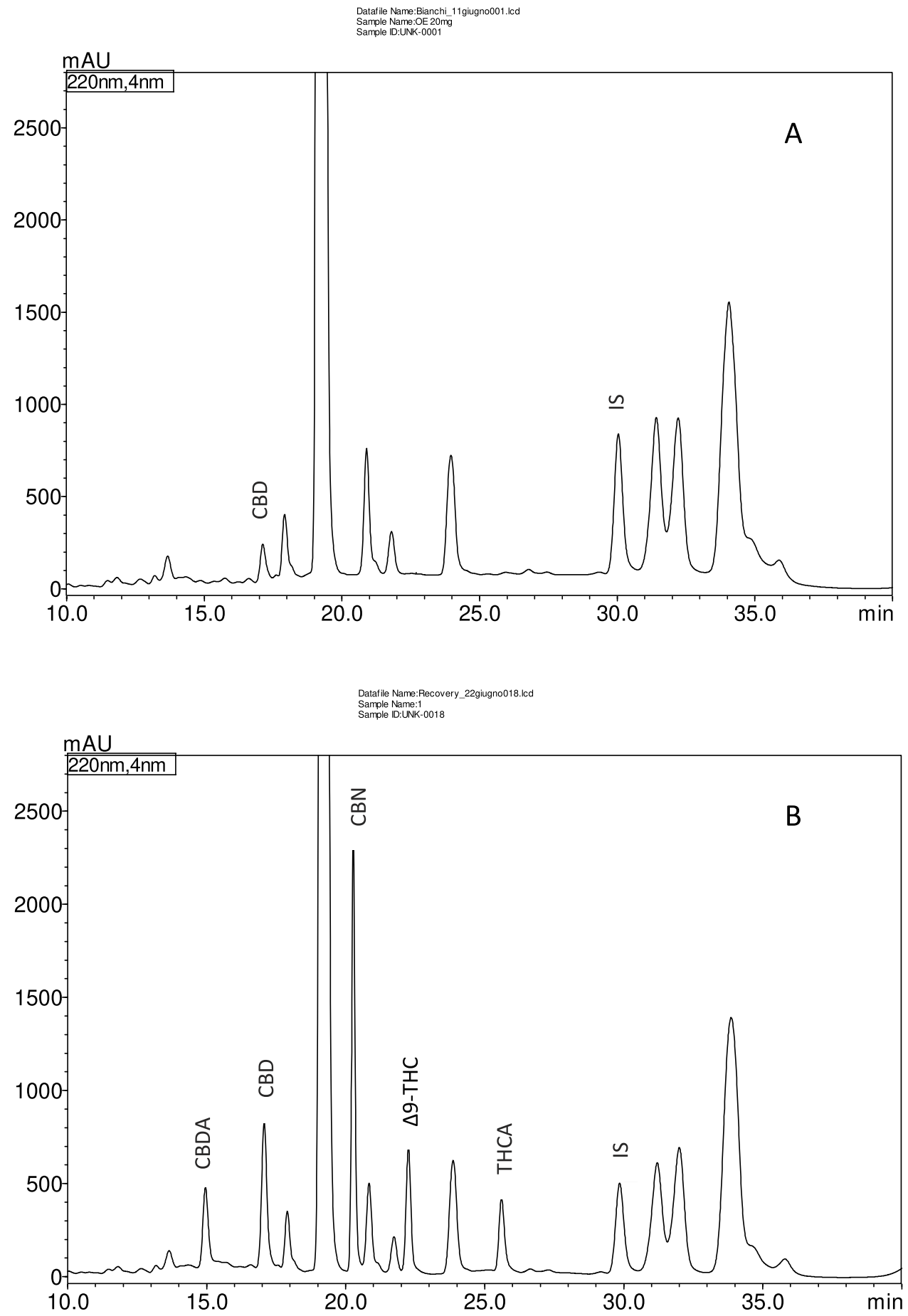

identified by comparison of the chromatographic retention time and UV spectra with the standard compounds.

The average hemp EO yield was $0.25 \pm 0.03 \%(\mathrm{v} / \mathrm{w}$, d.m.) $(n=5)$ similar to literature data reported for Cannabis sativa L. EO obtained by hydrodistillation (Hillig 2004; Nissen et al. 2010; Bertoli et al. 2010; Fiorini et al. 2019; Ascrizzi et al. 2019). The most abundant cannabinoid in hemp EO samples was CBD with an average concentration of $1074 \pm 62 \mathrm{mg} \mathrm{kg}^{-1}(n=5)$. This result is in agreement with the values reported by other authors (Bertoli et al. 2010; Ascrizzi et al. 2019) for EO obtained using the same extraction method (hydrodistillation) from different varieties and analyzed by GC-MS. On the contrary, the CBD concentration obtained in the present work was much lower than that obtained by Fiorini et al. (2019) (> 40,000 $\mathrm{mg} \mathrm{kg}^{-1}$ ); however, these authors adopted different sample pre-treatments, including the exposure of dried inflorescences to microwave heating at $900 \mathrm{~W}$ 
power for $1 \mathrm{~min}$, which proved to be the best method to increase the CBD content in EO.

Regarding the amount of the other cannabinoids in hemp EO, their concentration was lower than LOD.

\section{Method Performance}

\section{Selectivity}

By comparison of the EO and HQC sample chromatograms reported in Fig. 2 and the UV spectra of the compounds (Fig. 1) and by the purity check, no chromatographic interferences were observed between the cannabinoids and other compounds eluted in the region of interest, evidencing a good selectivity of the method.

\section{Calibration Parameters—Linearity—LOD and LOQ}

The calibration results of the method are reported in Table 1 . The calibration curves were linear over the concentration range $0.5-100 \mathrm{mg} \mathrm{L}^{-1}$ with determination coefficients $\left(R^{2}\right)$ higher than 0.999 for all cannabinoids; moreover, statistical analysis through ANOVA showed significant linear regression without deviation. The LOD ranged between 0.11 and $0.16 \mathrm{mg} \mathrm{L}^{-1}$ and the LOQ between 0.35 and $0.48 \mathrm{mg} \mathrm{L}^{-1}$ (Table 1).

\section{Accuracy and Precision}

Recovery tests were performed by using the quality control solutions, LQC, MQC, and HQC, and the results ranged from 78 to $100 \%$ (Table 2), indicating a satisfactory accuracy of the proposed method. Intra-day precision was determined at the same concentration levels with RSD $<4 \%$ evidencing a good repeatability (Table 2 ). Intermediate precision was measured at two concentration levels, LQC and HQC, over a period of 3 days with satisfactory RSD in the range $4-10 \%$ and $5-10 \%$ for LQC and HQC, respectively.
Table 2 Precision and recovery for the five cannabinoids

\begin{tabular}{llllll}
\hline Compound & $\begin{array}{l}\text { Concen- } \\
\text { tration } \\
\text { level }\end{array}$ & Precision RSD (\%) & Recovery & \\
& & & & & \\
\hline \multirow{4}{*}{$\mathrm{mg} \mathrm{g}^{-1}$} & Intra-day & Inter-day & Mean $(\%)$ & RSD (\%) \\
& 0.2 & 3.60 & 10.40 & 98 & 16 \\
& 1.0 & 0.99 & - & 83 & 12 \\
& 2.5 & 2.00 & 6.32 & 81 & 11 \\
CBD & 1.0 & 3.30 & - & 90 & 13 \\
& 5.0 & 1.84 & 9.80 & 86 & 8 \\
CBN & 0.2 & 3.00 & 3.75 & 97 & 12 \\
& 1.0 & 2.31 & - & 90 & 12 \\
& 5.0 & 0.83 & 4.80 & 95 & 9 \\
$\Delta 9-\mathrm{THC}$ & 0.2 & 3.00 & 9.72 & 99 & 13 \\
& 1.0 & 2.04 & - & 84 & 12 \\
& 5.0 & 0.83 & 5.22 & 79 & 7 \\
THCA & 0.2 & 2.00 & 9.55 & 100 & 16 \\
& 1.0 & 2.10 & - & 86 & 14 \\
& 2.5 & 0.92 & 7.75 & 78 & 8 \\
\hline
\end{tabular}

$R S D$, relative standard deviation

\section{Stability}

The EO samples were stable for 7 days at room temperature and 90 days at $-20^{\circ} \mathrm{C}$.

\section{Robustness}

The robustness of the method was evaluated by analyzing the MQC sample before and after small variations of the chromatographic parameters. Changes in flow rate $0.40 \pm$ $0.05 \mathrm{~mL} \mathrm{~min}{ }^{-1}$ and column temperature $25 \pm 5{ }^{\circ} \mathrm{C}$ did not influence the analytical results. The effect of perturbation of flow rate and column temperature on the concentrations of the cannabinoids is reported as contour plots in Fig. 3. The data have been normalized between 0 and 1. Darker regions indicate the highest variations in quantification. $\Delta 9$-THC showed the highest relative variation as response to temperature and flow rate modification, whereas CBD, CBDA, and
Table 1 Calibration parameters of the method

\begin{tabular}{llllll}
\hline Compound & $\begin{array}{l}\text { Concentration range } \\
\left(\mathrm{mg} \mathrm{L}^{-1}\right)\end{array}$ & $R^{2}$ & RRF & LOD $\left(\mathrm{mg} \mathrm{L}^{-1}\right)$ & LOQ $\left(\mathrm{mg} \mathrm{L}^{-1}\right)$ \\
\hline CBDA & $0.5-100$ & 0.9999 & 1.344 & 0.16 & 0.48 \\
CBD & $0.5-100$ & 0.9995 & 1.850 & 0.11 & 0.35 \\
CBN & $0.5-100$ & 0.9997 & 1.053 & 0.13 & 0.40 \\
$\Delta 9-$ THC & $0.5-100$ & 0.9997 & 1.767 & 0.12 & 0.38 \\
THCA & $0.5-100$ & 0.9993 & 1.328 & 0.15 & 0.47 \\
\hline
\end{tabular}

$R^{2}$, coefficient of determination; $R R F$, relative response factor 
Fig. 3 Contour plot in robustness: effect of perturbation on flow rate and oven temperature on cannabinoids quantification. $\mathrm{NR}$, normalized response
THC

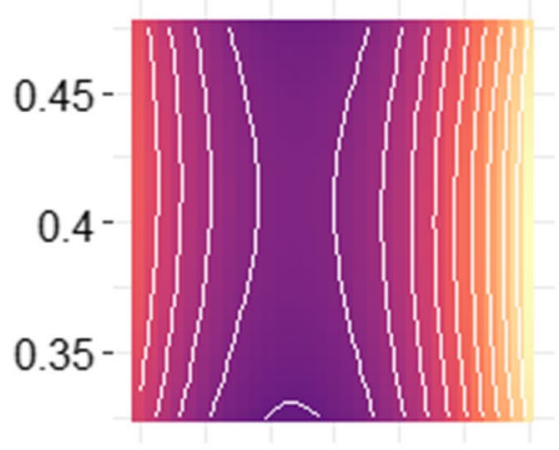

CBDA

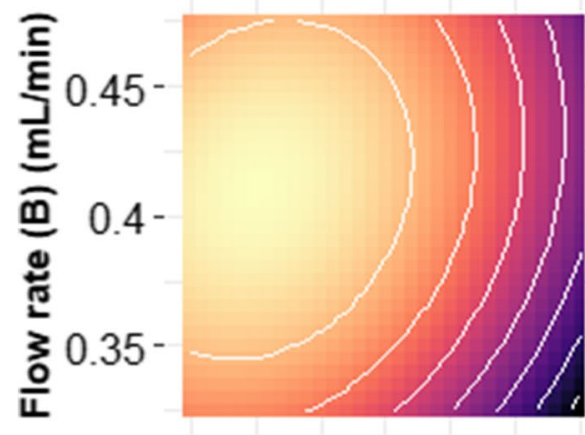

CBD

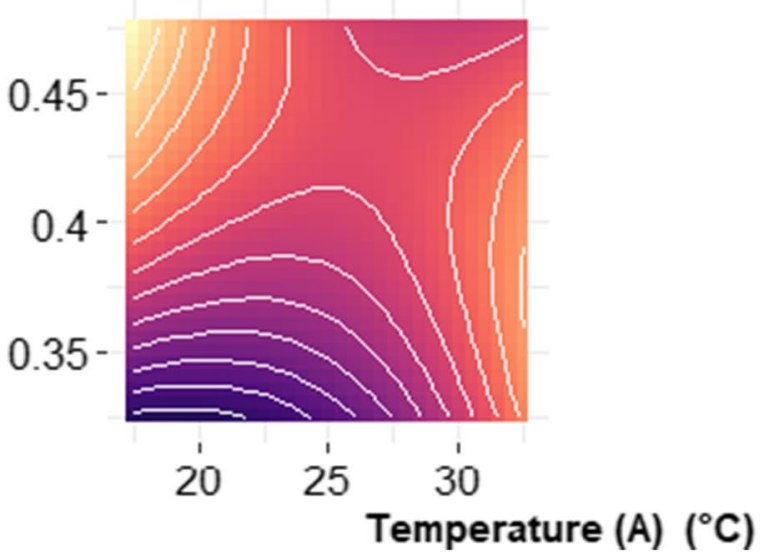

THCA

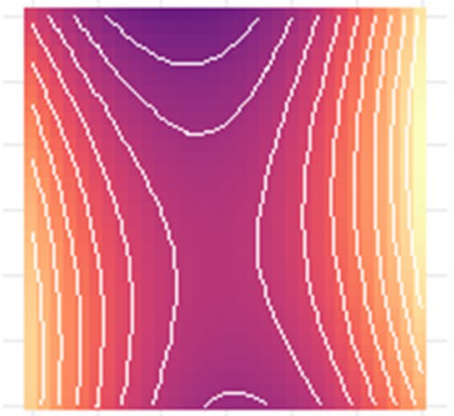

CBN

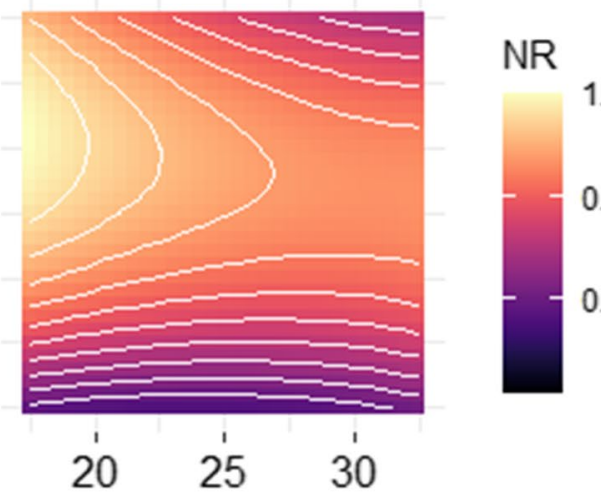

CBN were the least sensitive to variation in the chromatographic conditions.

\section{Conclusions}

The widespread use of hemp EO in the pharmaceutical, nutraceutical, food, and cosmetic sectors demands for reliable and simple analytical methods for its characterization, in particular, the quantification of CBD, the most abundant cannabinoid in hemp EO. Moreover, the acid forms and CBN concentrations are time- and temperature-dependent and CBN, which is considered a degradation product, could indicate the quality level of an industrial product. In this work, a new HPLC-PDA method has been developed for CBDA, CBD, CBN, $\triangle 9$-THC, and THCA quantification in hemp EO, a matrix less investigated with respect to other hemp-derived products. This analytical method evidenced good linearity, accuracy, and robustness and appears adequate for the quality control of hemp EO. The method was applied to the analysis of hemp EO obtained by hydrodistillation, but has much wider applications as it allows to quantify both the acidic and neutral forms of the cannabinoids in different hemp extracts, regardless of the preparation method adopted. 
Acknowledgements The authors would like to thank Fabio Zuliani for hemp field cultivation and data collection and Dr. Gaia Dorigo and Dr. Marco Vuerich for sampling and distillation of hemp inflorescences.

Funding Open access funding provided by Università degli Studi di Udine within the CRUI-CARE Agreement. The Agenzia regionale per lo Sviluppo Rurale del Friuli Venezia Giulia (ERSA - Friuli Venezia Giulia Regional Agricultural Services, Gorizia, Italy) supported this work (grant number CUP G24I19000620002).

Data Availability The datasets generated and/or analyzed during the current study are available from the corresponding author on reasonable request.

\section{Declarations}

Ethics Approval and Consent to Participate This article does not contain any studies with human participants or animals performed by any of the authors.

Competing Interests Barbara Piani declares that she has no conflict of interest. Claudio Ferfuia declares that he has no conflict of interest. Renzo Bortolomeazzi declares that he has no conflict of interest. Giancarlo Verardo declares that he has no conflict of interest. Mario Baldini declares that he has no conflict of interest.

Open Access This article is licensed under a Creative Commons Attribution 4.0 International License, which permits use, sharing, adaptation, distribution and reproduction in any medium or format, as long as you give appropriate credit to the original author(s) and the source, provide a link to the Creative Commons licence, and indicate if changes were made. The images or other third party material in this article are included in the article's Creative Commons licence, unless indicated otherwise in a credit line to the material. If material is not included in the article's Creative Commons licence and your intended use is not permitted by statutory regulation or exceeds the permitted use, you will need to obtain permission directly from the copyright holder. To view a copy of this licence, visit http://creativecommons.org/licenses/by/4.0/.

\section{References}

Aizpurua-Olaizola O, Soydaner U, Öztürk E et al (2016) Evolution of the cannabinoid and terpene content during the growth of Cannabis sativa plants from different chemotypes. J Nat Prod 79:324331. https://doi.org/10.1021/acs.jnatprod.5b00949

Andre CM, Hausman J-F, Guerriero G (2016) Cannabis sativa: the plant of the thousand and one molecules. Front Plant Sci 7. https:// doi.org/10.3389/fpls.2016.00019

Ascrizzi R, Ceccarini L, Tavarini S et al (2019) Valorisation of hemp inflorescence after seed harvest: cultivation site and harvest time influence agronomic characteristics and essential oil yield and composition. Ind Crop Prod 139:111541. https://doi.org/10. 1016/j.indcrop.2019.111541

Bedini S, Flamini G, Cosci F et al (2016) Cannabis sativa and Humulus lupulus essential oils as novel control tools against the invasive mosquito Aedes albopictus and fresh water snail Physella acuta. Ind Crop Prod 85:318-323. https://doi.org/10.1016/j.indcrop. 2016.03.008

Bertoli A, Tozzi S, Pistelli L, Angelini LG (2010) Fibre hemp inflorescences: from crop-residues to essential oil production. Ind Crop Prod 32:329-337. https://doi.org/10.1016/j.indcrop.2010.05.012
Callaway JC (2004) Hempseed as a nutritional resource: an overview. Euphytica 140:65-72. https://doi.org/10.1007/s10681-004-4811-6

Citti C, Braghiroli D, Vandelli MA, Cannazza G (2018) Pharmaceutical and biomedical analysis of cannabinoids: a critical review. J Pharm Biomed Anal 147:565-579. https://doi.org/10.1016/j.jpba. 2017.06.003

Clarke RC, Merlin MD (2016) Cannabis domestication, breeding history, present-day genetic diversity, and future prospects. Crit Rev Plant Sci 35:293-327. https://doi.org/10.1080/07352689.2016. 1267498

Commission of the European Communities (2004) Commission Regulation (EC) No 796/2004 Laying Down Detailed Rules for the Implementation of Cross-Compliance, Modulation, and the Integrated Administration and Control System Provided for in Council Regulation (ED) No 1782/2003 Establishing Common Rules for Direct Support Schemes Under the Common Agricultural Policy and Establishing Certain Support Schemes for Farmers. Brussels: European Union.

Commissione Permanente per la Revisione e la Pubblicazione della Farmacopea Ufficiale (2008) XII edizione della Farmacopea ufficiale della Repubblica italiana. Istituto poligrafico e Zecca dello Stato, Roma

Corroon J, Phillips JA (2018) A cross-sectional study of cannabidiol users. Cannabis Cannabinoid Res 3:152-161. https://doi.org/10. 1089/can.2018.0006

De Backer B, Debrus B, Lebrun P et al (2009) Innovative development and validation of an HPLC/DAD method for the qualitative and quantitative determination of major cannabinoids in cannabis plant material. J Chromatogr B 877:4115-4124. https://doi.org/ 10.1016/j.jchromb.2009.11.004

European Parliament and of the Council (2013) Regulation (EU) No 1307/2013 of the European Parliament and of the Council of 17 December 2013 establishing rules for direct payments to farmers under support schemes within the framework of the common agricultural policy and repealing Council Regulation (EC) No 637/2008 and Council Regulation (EC) No 73/2009

Fiorini D, Molle A, Nabissi M et al (2019) Valorizing industrial hemp (Cannabis sativa L.) by-products: cannabidiol enrichment in the inflorescence essential oil optimizing sample pre-treatment prior to distillation. Ind Crop Prod 128:581-589. https://doi.org/10. 1016/j.indcrop.2018.10.045

Fiorini D, Scortichini S, Bonacucina G et al (2020) Cannabidiolenriched hemp essential oil obtained by an optimized microwaveassisted extraction using a central composite design. Ind Crop Prod 154:112688. https://doi.org/10.1016/j.indcrop.2020.112688

Glivar T, Eržen J, Kreft S et al (2020) Cannabinoid content in industrial hemp (Cannabis sativa L.) varieties grown in Slovenia. Ind Crops. Prod 145:112082. https://doi.org/10.1016/j.indcrop.2019.112082

Górski R, Sobieralski K, Siwulski M (2016) The effect of hemp essential oil on mortality Aulacorthum solani Kalt and Tetranychus urticae Koch. Ecol Chem Eng S 23:505-511

Happyana N, Kayser O (2016) Monitoring metabolite profiles of Cannabis sativa $\mathrm{L}$. trichomes during flowering period using $1 \mathrm{H}$ NMRbased metabolomics and real-time PCR. Planta Med 82:12171223. https://doi.org/10.1055/s-0042-108058

Hazekamp A (2007) Cannabis: extracting the medicine. Proefschrift Universiteit Leiden The Netherlands, Phdthesis

Hillig KW (2004) A chemotaxonomic analysis of terpenoid variation in Cannabis. Biochem Syst Ecol 32:875-891. https://doi.org/10. 1016/j.bse.2004.04.004

Kim E-S, Mahlberg PG (1991) Secretory cavity development in glandular trichomes of Cannabis sativa L. (Cannabaceae). Am J Bot 78:220-229. https://doi.org/10.1002/j.1537-2197.1991.tb15749.x

Koren A, Sikora V, Kiprovski B et al (2020) Controversial taxonomy of hemp. Genetika 52:1-13. https://doi.org/10.2298/gensr2001001k 
Mediavilla V, Steinemann S (1997) Essential oil of Cannabis sativa L. strains. J Int Hemp Assoc 4:82-84

Meier C, Mediavilla V (1998) Factors influencing the yield and the quality of hemp (Cannabis sativa L.) essential oil. J Int Hemp Assoc 5:16-20

Ministero della Salute (2020) Decreto 4 novembre 2019. Definizione di livelli massimi di tetraidrocannabinolo (THC) negli alimenti. In Gazzetta Ufficiale della Repubblica Italiana, Serie generale$\mathrm{N}^{\circ} 11,15$ gennaio 2020 Istituto Poligrafico e Zecca dello Stato, Roma.

Mukhtar T, Kayani MZ, Hussain MA (2013) Nematicidal activities of Cannabis sativa L. and Zanthoxylum alatum Roxb. against Meloidogyne incognita. Ind Crop Prod 42:447-453. https://doi.org/10. 1016/j.indcrop.2012.06.027

Nafis A, Kasrati A, Jamali CA et al (2019) Antioxidant activity and evidence for synergism of Cannabis sativa (L.) essential oil with antimicrobial standards. Ind Crop Prod 137:396-400. https://doi. org/10.1016/j.indcrop.2019.05.032

Nissen L, Zatta A, Stefanini I et al (2010) Characterization and antimicrobial activity of essential oils of industrial hemp varieties (Cannabis sativa L.). Fitoterapia 81:413-419. https://doi.org/10. 1016/j.fitote.2009.11.010

Novak J, Zitterl-Eglseer K, Deans SG, Franz CM (2001) Essential oils of different cultivars of Cannabis sativa $\mathrm{L}$. and their antimicrobial activity. Flavour Fragr J 16:259-262. https://doi.org/10.1002/ffj. 993

Pacifico D, Miselli F, Carboni A et al (2007) Time course of cannabinoid accumulation and chemotype development during the growth of Cannabis sativa L. Euphytica 160:231-240. https://doi.org/10. 1007/s10681-007-9543-y

Poleg S, Golubchik P, Offen D, Weizman A (2019) Cannabidiol as a suggested candidate for treatment of autism spectrum disorder. Prog Neuro-Psychopharmacol Biol Psychiatry 89:90-96. https:// doi.org/10.1016/j.pnpbp.2018.08.030

R Core Team (2020) R: A Language and Environment for Statistical Computing. R Foundation for Statistical Computing, Vienna

Raharjo TJ, Verpoorte R (2004) Methods for the analysis of cannabinoids in biological materials: a review. Phytochem Anal 15:79-94. https://doi.org/10.1002/pca.753
Rehman MSU, Rashid N, Saif A et al (2013) Potential of bioenergy production from industrial hemp (Cannabis sativa): Pakistan perspective. Renew Sust Energ Rev 18:154-164. https://doi.org/10. 1016/j.rser.2012.10.019

Sandler LN, Gibson KA (2019) A call for weed research in industrial hemp (Cannabis sativa L). Weed Res 59:255-259. https://doi.org/ $10.1111 /$ wre. 12368

Synowiec A, Rys M, Bocianowski J et al (2016) Phytotoxic effect of fiber hemp essential oil on germination of some weeds and crops. J Essent Oil Bear Plants 19:262-276. https://doi.org/10.1080/ 0972060x.2015.1137236

Vági E, Balázs M, Komóczi A et al (2019) Cannabinoids enriched extracts from industrial hemp residues. Period Polytech Chem Eng 63:357-363. https://doi.org/10.3311/ppch.12896

Vuerich M, Ferfuia C, Zuliani F et al (2019) Yield and quality of essential oils in hemp varieties in different environments. Agronomy 9:356. https://doi.org/10.3390/agronomy9070356

Wanas AS, Radwan MM, Chandra S et al (2020) Chemical composition of volatile oils of fresh and air-dried buds of Cannabis chemovars, their insecticidal and repellent activities. Nat Prod Commun 15:1934578X2092672. https://doi.org/10.1177/19345 $78 \times 20926729$

Wanas AS, Radwan MM, Mehmedic Z et al (2016) Antifungal activity of the volatiles of high potency Cannabis sativa L. against Cryptococcus neoformans. Rec Nat. Prod 10(214)

Wielgusz K, Heller K, Byczyńska M et al (2012) The assessment of fungistatic effect of hemp essential oil as seed dressing, depending on the composition. J Res Appl Agric Eng 57:183-187

Yuan B, Zhao D, Kshatriya D et al (2020) UHPLC-QqQ-MS/MS method development and validation with statistical analysis: determination of raspberry ketone metabolites in mice plasma and brain. J Chromatogr B 1149:122146. https://doi.org/10.1016/j. jchromb.2020.122146

Publisher's Note Springer Nature remains neutral with regard to jurisdictional claims in published maps and institutional affiliations. 